\title{
Del saber y de la libertad. El argumento de Isaiah Berlin contra el determinismo (II)
}

\author{
JUAN BOSCO DÍAZ-URMENETA MUÑOZ \\ Universidad de Sevilla
}

\begin{abstract}
RESUMEN
La posición de 1 . Berlin sobre el determinismo fue recibida por muchos como un ataque al alcance de las ciencias humanas. Su argumentación, sin embargo, sugiere nuevas y sugerentes relaciones entre cl conocimiento y la libertad, además de una concepción específica de la lectura de la historia. En el presente ensayo, que se editará en dos partes, se analiza el argumento de $\mathbf{I}$ Berlin sobre el determinismo, situándolo en las dos discusiones sobre la historia que se desarrollaron tras la II Guerra Mundial.
\end{abstract}

$$
\text { PALABRAS CLAVE }
$$

DETERMINISMO-BERLIN

\section{AESTRACT}

1. Berlin's position on determinism was received by many authors as an attack on the human sciences. His interpretation, howevers suggests novel and stimulating relations between knowledge and freedom, together with a specific philosophy of history. This paper continucs the assessment of Berlin's argument on determinism, initiated in a previous essay. Thus, locates determinism within the two debates on history held after world war Il.

KEYWORDS

DETERMINISM-BERLIN

VII

EN EL CRUCE DE LOS DEBATES SOBRE LA HISTORIA que hemos estudiado-el primero en torno a la explicación histórica y a las peculiaridades del texto histórico, el 
segundo acerca del alcance de las leyes generales en la historia- el ensayo de Berlin, Historical Inevitability, destaca sobre todo por presentar una tesis fuerte: una lectura determinista de la acción humana y del acontecer histórico es inadecuada. La tesis se opone tanto a la unidad de método y objeto que buscan los defensores de la Ciencia unificada, como a las filosofías de la historia que confían en encontrar leyes del desarrollo histórico o fórmulas para un desenvolvimiento unitario del acontecer: provoca las críticas de Nagel y las de Carr. El alcance de la tesis alerta también a otros pensadores que advierten en ella un debilitamiento de la objetividad de las ciencias humanas; por eso es necesario considerar una segunda tesis que se plantea en el ensayo, tan importante como la primera, y que es una noción de objetividad basada en la comunicación'.

De la primera de esas tesis, Berlin afirma que no es una refutación del determinismo, sino que sólo señala que si el determinismo «alguna vez se convierte en una creencia aceptada por muchos y entra a formar parte de la estructura del pensamiento y la conducta de la gente, ciertos conceptos, palabras y creencias, profundamente inmersas en el lenguaje y pensamiento de los hombres, dejarían de ser operantes o habría que cambiar drásticamente su uso y su significado ${ }^{2}$. Tales conceptos y creencias son los que diseñan el ámbito de la opción, la imputación de responsabilidad, las alternativas de acción.

Antes de examinar la argumentación, permítaseme señalar que el planteamiento de Berlin desborda los debates que analizamos en la primera parte de este trabajo. Su propuesta es desprender a la acción humana de cualquier trama que le sea exterior y hacerle recuperar el momento de indeterminación propio de la opción o, al menos, la apertura ante alternativas diversas.

El problema tiene evidentes raíces morales, pero Berlin lo sitúa en una perspectiva crítica, epistemológica, para señalar que el pensamiento occidental moderno sobrevaloró de tal modo el conocimiento que minimizó el papel de la voluntad humana.

Berlin piensa que el nacimiento de la ciencia moderna debilitó la confianza en las antiguas visiones ontológicas y teológicas, pero que su alcance crítico se vio mermado porque las leyes científicas se tomaron como un nuevo saber completo que prometía un esclarecimiento pleno de la realidad ${ }^{3}$. La ciencia

1 Las opiniones de Carr pueden verse en E. H. Carr 1984, pp. 59, 61, 69 n., 103, 123-127, 133. 139, 158, 172-174. La obra de Carr surge de unas conferencias celebradas en 1961. En cuanto a la discusión sobre la objetividad, además de los trabajos de S. Hampshire, Nagel y P. Gardiner 1977, así como en White, 1956; pueden verse otros citados en la Introducción a I. Berlin 1988 y en mi Individuo y racionalidad moderna. Una lectura de Isaiah Berlin. Sevilla: Universidad de Sevilla, 1994.

2 I. Berlin 1988, pp. 11, 29.

3 I. Berlin 1990, p. 214. 
ofrecía «un grupo de principios universales e inalterables» que podían organizar todos los aspectos de la vida y la realidad, y garantizar una existencia ordenada: «sólo por apartarse de aquellos principios los hombres caían en el delito, el vicio y la miseria ${ }^{4}$. Lo que la capacidad racional autónoma descubría, fraguaba en moldes demasiado viejos, los de la filosofía tradicional de Occidente que atribuía a la realidad una estructura última que la búsqueda racional podía encontrar. La creencia ilustrada en la existencia de «una estructura de las cosas, una rerum natura", que llegaría a descubrir la razón con tal que siguiera el método - el camino-adecuado 5 , convertía a la naturaleza en nuevo libro sagrado administrado por los detentadores del nuevo saber, los expertos ilustrados, que gozaban de una autoridad próxima a la que pidiera Platón para el ReyFilósofo y las iglesias para sus sacerdotes.

Berlin analiza en distintas ocasiones este desplazamiento de la racionalidad ilustrada hacia una nueva ontología y piensa que su elemento decisivo es la confianza puesta en el conocimiento. En un texto recientemente editado6, Berlin subraya que la comunidad ilustrada fue mucho más heterogénea en sus opiniones de lo que suele creerse; pese a ello, añade, todos estaban de acuerdo en el poder del conocimiento, en que «reality is knowable, and that knowledge and only knowledge liberates, and absolute knowledge liberates absolutely»? Es la misma convicción que alimentara la corriente central del pensamiento Occidental, y que llega a anular con su «Virtue is knowledge» los dispersos destellos de cuantos hicieron del saber un atrevimiento 8 .

Estas esperanzas puestas en el conocimiento llegan a desnaturalizar la acción al hundir en el olvido que su ámbito lo cruzan siempre las alternativas y en mayor o menor grado, la incertidumbre. Explicar una acción -lo sabe el historiador y lo hace el novelista- exige dar cuenta de alternativas, indagar cuáles se descartan y por qué; qué valores, preferencias o fines se contemplaron, bajo qué fuerzas se actuó; con qué consecuencias y cuáles de éstas se previeron; qué riesgos se afrontaron, etc. Poco de esto se advierte por el intelectualismo para quien «explicar las cosas es subsumirlas en fórmulas generales y representarlas como ejemplos de leyes que valen para un número infinito de casos, de tal manera que con el conocimiento de todas las leyes pertinentes y un suficiente

4 I. Berlin 1983c, p. 62.

5 I. Berlin 1983b, p. 11.

6 I. Berlin 1993, pp. 26-30.

7 I. Berlin 1988, p. 147

8 Merece la pena recordar aquí lo que Kant dice de la Ilustración como autonomía del propio juicio; basta recordar I. Kant 1981b, passim. A propósito de la máxima Sapere Aude, hay un interesante estudio de Ginzburg (C. Ginzburg 1994, pp. 94-116), en el que, a través de emblemas, se sugiere una evolución de la autonomía del conocimiento y el atrevimiento del saber. 
número de hechos también pertinentes será posible decir no sólo lo que sucede, sino también por qué»? 9 .

Esta simplificación causalista, tiene su homólogo en las posiciones teleológicas, para las que explicar una acción es «descubrir su finalidad»10, y en las de inspiración organicista que tratarán de buscar «su función»11. El conocimiento se convierte entonces en supuesta omnisciencia que sirve de pantalla teórica y/o de coartada práctica a la acción y se hace «falsa conciencia» o «mala fe», porque el problema de la acción se desplaza -en el sentido fuerte y estricto de Freud- de modo que sus componentes subjetivos -con su riesgo e incertidumbre- se transfieren a una zona templada, ordenada por tramas racionalizables, en la que la tutela del conocimiento disuelve el malestar de la opción, el aguijón del deseo o el desconcierto ante valores en conflicto.

$\mathrm{He}$ dicho que la crítica de Berlin es epistemológica porque su planteamiento quiere mostrar cuanto en este desplazamiento, en esta racionalización de la acción, quebranta la crítica más elemental. Algunos análisis de este tipo otorgan a una categoría del pensamiento rango de realidad; la categoría, entonces, no organiza los componentes empíricos del acontecer sino que los oculta. Otras veces, la red categorial se aplica no al esclarecimiento de una situación, sino a recortar de ella los riesgos aunque así también se la despoje de su complejidad y riqueza. Berlin define el primero de esos caminos con palabras de Hamann: se pretende estar hablando de cosas, cuando en realidad lo estamos haciendo sobre conceptos o palabras 12 ; cree que el segundo es característico de ciertas filosofías, tentadas por la omnisciencia, que se sitúan a la vez dentro y fuera de las categorías. Ambos procedimientos son formas, dice, de reificación 13 , una hechura del pensamiento se ha convertido en algo presuntamente real y así, lo que hubiera podido esclarecer las cosas sirve para ocultarlas y para encubrir la capacidad humana de idear y expresar. Cuando se trata del análisis de la acción o del acontecer, ambas consecuencias se recubren y refuerzan ${ }^{14}$ y la queja del objeto frente al concepto que lo deforma es la de Belinsky contra Hegel: «si llegara a lo más alto de la escala del desarrollo

9 I. Berlin 1988, p. 123.

10 lbid., p. 119.

11 lbid., p. 122.

$12 \mathrm{El}$ aforismo de Hamann se aplica en I. Berlin 1988, pp. 107-108, a Comte.

13 I. Berlin 1993, pp. 83-84.

14 Berlin evita exponer su idea de reificación en moldes dialécticos, recurre a Diderot, Rousseau o Vico, sobre todo (I. Berlin 1980, pp. 61, 67). Sin embargo su análisis guarda afinidades con Adorno: ambos coinciden en negar al concepto su inocencia. Berlin fue amigo de Adorno, compartían una gran afición en común, la música. Pese a ello confiesa a Jahanbegloo no haber entendido nunca sus escritos. 
humano, aún habría de pedir a Hegel que me explicara todas las víctimas de la vida y de la historia»15.

La desfiguración del conocimiento tiene evidentes consecuencias éticas: la rendición de la opción, su entrega a una generalidad que le es exterior y ajena. Berlin se mantiene en un terreno teórico porque quiere plantear un debate de ideas: cuando aparecen conflictos radicales entre valores o se advierte que los costes de ciertas opciones pueden ser graves para los individuos o emergen pretensiones de autonomía en culturas hasta el momento ignoradas, no es lícito hacer desaparecer el filo de estos problemas bajo las determinaciones -causales o teleológicas- de un pensamiento que se refugia en generalidades, y olvidar la propia capacidad de pensar y posicionarse. Berlin quiere zarandear esta paz del pensamiento en la que ve la trampa de la ideología ${ }^{16}$.

La crítica de Berlin, sin embargo, plantea un problema: si las formas particulares del acontecer y los caminos indiviaduales de acción impugnan las generalidades como malas racionalizaciones ¿es posible alguna esfera de objetividad para su consideración o deberán permanecer una y otro en un insuperable subjetivismo o en un mosaico de interpretaciones relativas?17. A esto responde la segunda tesis de Berlin: la historia sugiere una idea de objetividad que brota de la comunicación. Esta comunicación no se apoya, como en Popper, en la identidad racional sino en la posibilidad de reconocer en las diferentes formas de establecer el objeto y en los distintos modos de organizar la vida, la misma capacidad categorial humana. Examinaré sucesivamente ambas tesis.

VIII

El argumento de Berlin contra el determinismo no intenta probar su falsedad sino la inconsistencia lógica entre un mundo pensado exclusivamente en conceptos deterministas y las estructuras lingüísticas y categoriales con las que hablamos -y pensamos-al atribuir responsabilidad o eximir de ella, dilucidar alternativas de acción o enfrentar una opción. Estas estructuras ahorman el trabajo del historiador, del juez y el novelista y la relación entre médico y enfermo; están en el lenguaje y la reflexión como el espacio, el tiempo o los números ${ }^{18}$. La

15 I. Berlin 1979, p. 323.

16 En I. Berlin 1988, pp. 98 ss se analizan algunas cuestiones que son características de la época a juicio de Berlin. En ellas, en la planificación o el colonialismo, Berlin señala una precedencia de planteamientos doctrinarios sobre los análisis empíricos. El problema no es exclusivo, sin embargo, de las posiciones no conservadoras: en I. Berlin 1988, p. 109 se dice que el conservadurismo y el liberalismo de la época son muy miopes ante las protestas anticolonialistas.

17 P. Gardiner 1977 y F. Momigliano 1976.

18 I. Berlin 1988, pp. $137,139$. 
inconsistencia entre ambas estructuras no implica un juicio sobre la naturaleza determinista o no de las cosas -por eso Berlin dice que él no prueba la falsedad del determinismo- sino que ciertos ámbitos de la experiencia, si han de mantener el sentido que les damos, escapan a la conceptualización del determinismo.

Esta diversidad de ámbitos de experiencia no la advierte Nagel, para quien, la unidad de objeto del saber implica que el lenguaje debe ser siempre descriptivo de estados del mundo ${ }^{19}$. Esta reducción de las posibilidades del lenguaje es una exigencia del criterio de significado, una restricción que ya Berlin criticó en 1939, argumentando que un lenguaje así concebido era inservible para la historia. La razón central era, sin embargo, de más calado y venía a decir que lo que no advierten los defensores del criterio de significado es que los enunciados son antes inteligibles que verificable ${ }^{20}$ y desde la inteligibilidad habrá que atribuir sentido no sólo a la oración con datos empíricos observables, sino a toda la que exprese algo que puedo concebir lógicamente como existente. Y ello quiere decir: 1 ) algo de lo que puedo tener experiencia no sólo observacional sino por la memoria, la imaginación o «cualquier forma de familiarización con el objeto» y 2) expresado de modo categorialmente coherente, es decir, no sólo con corrección sintáctica, sino que promete sólo lo que puede realizar: habla de una experiencia y lo hace con un lenguaje que se limita a tal experiencia y a lo que en ella es comunicable 21 .

Con esto, Berlin está proponiendo que el conocimiento es más construcción coherente que correspondencia con la realidad y que la experiencia brota de múltiples relaciones con el objeto, sin recortes ni exclusivismo. El trabajo de la experiencia no se reduce a una suma o sucesión de descripciones sino que, si alcanza valor cognoscitivo, es porque expresa con coherencia esas múltiples relaciones de modo que los demás puedan compartirla. Esta articulación se hace mediante estructuras categoriales, que son las que inspiran a la sintaxis lógica y son por tanto anteriores a ésta. Conocer, por tanto, es, antes que atenerse a reglas lógicas y a la observación, una actividad que modela la experiencia, la ilumina desde ángulos muy diversos y propone sus resultados a seres que tienen la misma capacidad de indagación y expresión inteligentes.

No hay renuncia al empirismo: mantiene la necesidad de verificación y de crítica conceptual pero situándolas en un marco más amplio que desborda al observador ideal del fenomenalismo y también al sujeto del entendimiento kantiano. En efecto, la articulación de la experiencia que se propone modifica la noción tradicional de categorías que no pueden considerarse surcos eternos

19 Nagel pone algunos ejemplos de lo que para él significa el concepto idiográfico que atribuye a la historia. El análisis de estos ejemplos apenas permite separar su uso de la descripción.

20 I. Berlin 1983a, p. 69.

21 ibid., p. 70. 
del pensamiento -si reconocemos que nuestro conocimiento es histórico-ni tampoco catálogos cerrados y excluyentes -porque el conocimiento es inventivo-. Pensadores como Marx, Freud o Einstein destacan sobre todo porque sus nuevas categorías no sólo esclarecen el objeto de su investigación, sino que se extienden de un campo a otro de la experiencia arrojando nueva luz sobre ellos. Esta misma consideración separa a las categoría del estereotipo que las convierte en moldes objetivos en los que la experiencia se condensa y las acerca a una red que, aunque no puede cambiarse caprichosamente, el sujeto emplea tentativamente para organizar la experiencia. En otras palabras, las categorías se aproximan al lenguaje22: detienen el flujo de la experiencia y nombran, pero también conectan, como la metáfora, campos hasta entonces separados.

$\mathrm{Al}$ acercar así las categorías a los usos de lenguaje, la articulación de la experiencia posible se separa más aún de la descripción y adquiere rasgos del lenguaje realizativo de Austin 23 . El conocimiento se convierte en propuesta de experiencia inteligible gracias a un uso adecuado y reconocible de categorías. Berlin lo dice en un trabajo de 1950: las palabras no significan por «circunscribir trozos de realidad" sino porque tienen un uso reconocido: «sus usuarios saben cómo emplearlas y en qué circunstancias, para comunicar lo que deben comunicar» 24 . Obsérvese, por último, que los usos de lenguaje no son un catálogo de formas sino condensaciones posibles de la experiencia que no pueden determinarse $a$ priori.

Un conocimiento así es, desde el primer momento, reflexivo porque no pueden establecerse de antemano articulaciones privilegiadas de la experiencia ni datos que se consideren terminantes o últimos. En un nivel general, para examinar la validez de una oración habrá que examinar qué categorías se aplican, desde qué relación con el objeto y con qué rango de coherencia. En los análisis de acción, esto tiene concreciones especiales: en primer lugar, las peculiaridades de la acción serían ignoradas por un modelo lógico abstracto25; la reflexión, exigirá, además, poner en juego categorías que parecen englobar tanto al sujeto como al objeto: precisar, por ejemplo, las condiciones en las que puede hablarse de autoría, diferenciarlas de aquéllas en las que habría causa mayor o accidente y ambas, a su vez, de la imprudencia o la temeridad; sólo ese discernimiento puede separar lo que pudo ocurrir y no ocurrió de lo que no pudo ocurrir en ningún caso ${ }^{26}$. No es un recurso a la psicología. Es más bien la

22 Esta correlación puede verse sobre todo en I. Berlin 1980 y también en I. Berlin 1993 , Appendix.
23 J. L. Austin 1982, Conferencia IV.
24 1. Berlin 1983a, p. 144.
25 I. Berlin 1988, p. 139.
26 Ibid., p. 136. 
habilidad de quien consigue concitar muchos saberes y datos de modo que los hace confluir para dar cuenta de una acción. Es, si se quiere, capacidad de juicio. Los análisis de acción sólo en última instancia describen. La descripción es el final de un largo proceso de indagación de características tan complejas como las que acabamos de explicar. Del establecimiento de los hechos por un juez o del veredicto de un analista político no esperamos ni la fidelidad del cronista ni la eficacia predictiva de un agente de ventas, sino una propuesta que ilumine los cursos de acción porque logra unir muchos niveles de significado, resaltar valores y motivaciones, diseñar un denso mapa de las opciones posibles.

Este trabajo reflexivo se desliza, casi insensiblemente, a una pragmática. Análisis como al que me acabo de referir no existen en abstracto, sino que tienen un lugar en relaciones cognoscitivas bastante precisas. Al principio del epígrafe me referí a algunas figuras profesionales cuyo ejercicio exige un tipo de conocimiento bastante más rico que el que pudiera tener el observador de Laplace. Esta confluencia de reflexión y pragmática subtiende los conceptos weberianos llamadas «posibilidad objetiva» y «causación adecuada», ejemplos de explicaciones del acontecer que tienen en cuenta la complejidad de los procesos de acción. Weber los acuñó a partir de los trabajos de von Kries ${ }^{27}$, un fisiólogo atento a nexos interactivos, para aplicarlos a la historia y el derecho, porque estos dominios del saber piden más que la exclusión puramente lógica de alternativas o la subsunción bajo leyes formales o la identificación extensional de los datos, la conexión reflexiva que sabe valorar relevancias, idear tentativamente hipótesis en las que confluyan saberes muy distintos y atender a la especificidad del objeto que se estudia y que, en este caso, se mueve en un ámbito abierto.

El proceso descrito compendia la argumentación de Berlin que consiste en establecer que la acción, como objeto del conocimiento, es un objeto abierto y en subrayar las categorías y relaciones cognoscitivas -reflexivas y pragmáticas-bajo las que puede entenderse. El fenomenalismo no aceptará estas consideraciones; tampoco quienes piensen que conocer es llegar a una realidad última que un lenguaje adecuado podrá tematizar. Las filosofías de corte trascendental reconocerán que estamos ante un objeto que se separa de la noción trascendental de naturaleza -porque las categorías que lo organizan anclan en la reflexión y no en las determinaciones del entendimiento, y los saberes que lo esclarecen trabajan desde perspectivas cuya pragmática no es asimilable a la de la objetividad científica- pero podrán aceptar la legitimidad del procedimiento. Berlin, que se mueve en un cierto trascendentalismo, la establece porque cree que conocer es no sólo organizar la experiencia categorial y

27 M. Weber 1982, pp. 152, 154 y 170. 
lingüísticamente, sino aceptar sin recortes nuestras relaciones con el objeto. Su opción, en este sentido, tiene mucho que ver con el rango que otorga a la apertura de la acción. Examinaré de inmediato su alcance epistemológico. Los análisis no trascendentales conservan, para Berlin, la esperanza en algún lenguaje privilegiado. No traicionamos a Berlin si decimos, con Nietzsche, que tal lenguaje sería el de una nueva divinidad o el de los Hinterwelter, un lenguaje que escapa del mundo y del que si alguien espera algo es porque ya no se atreve ni siquiera a querer.

IX

Examinemos las críticas hechas desde planteamientos trascendentales. El aspecto decisivo del problema, como acabamos de ver, radica en qué clase de objeto es el de las ciencias humanas y qué relaciones mantenemos con él. Conocemos la opción de Berlin pero, como dijimos al inicio del artículo, excluir de antemano al objeto acción de la idea trascendental de naturaleza podría ser un modo de evasión. Hampshire 28 cree que las ciencias humanas pueden abordar su objeto tanto desde una perspectiva conceptual como reflexiva; tomar una u otra alternativa es una opción metodológica y no exige el supuesto de la libertad. Éste, en el argumento de Berlin, sería un elemento no justificado, un intruso metafísico que hace del razonamiento una metábasis eis állo génos al desplazar sin motivo a un objeto de la ciencia fuera de su ámbito.

Hampshire pone el ejemplo de un psicótico, al que podemos considerar como alguien que se ha retirado de la comunicación directa - de «un mundo prosaico, público y literal»-a la indirecta -a «un lenguaje metafórico, privado, poético»-. Podríamos concebir su terapia como un proceso en el que el paciente llegara a reconocer «la posibilidad de intercambio con el mundo y se sienta preparado para ello» 29 . Ahora bien, esto puede hacerse mediante una comprensión inmediata de la experiencia del paciente -es decir, reflexivamente-o bien indagando las causas ocultas de la enfermedad, lo que exige conceptos de elaboración de síntomas. Las dos vías son posibles. Hay que hacer una opción que Hampshire llama, con intención, tecnológica pues no implica más que aplicar el método más adecuado según la situación y los conocimientos científicos disponibles.

El objeto de las ciencias humanas tiene doble condición y Hampshire cree que podría abordarse con una formulación lógica adecuada, como la del contrafáctico enunciado en subjuntivo ${ }^{30}$. Permitiría unir oraciones determi-

28 Ver S. Hampshire, 1949, 1967, 1979. Ver también la discusión mantenida por Hampshire en Pears, D. F.: Freedom and the Will, Londres: Hogarth Press, 1965, pp. 80-104.

29 S. Hampshire 1967, p. 290.

30 S. Hampshire 1979. 
nísticas -regularidades objetivas de la ciencia-con un conocimiento reflexivo que dejara abierta las condiciones de su aplicación a situaciones concretas. Ambos conocimientos se complementan e iluminan. Se fija así la «doble visión" de las ciencias humanas, sin perder ninguna de sus dimensiones. Hampshire hace además una interesante observación: quien trata de aclarar con tales razonamientos sus propios cursos de acción pasa de la primera a la tercera persona, es decir, comienza indagando reflexivamente y termina descubriendo regularidades ${ }^{31}$, realiza una objetivación. que se produce mediante una retroalimentación que dispone de relevancias objetivas y las administra reflexivamente. Hampshire reconoce que quizá esto no sea posible sin la libertad pero eso no implica que ésta se tenga que incluir como elemento del razonamiento. Explicar la acción, concluye, exige las dos dimensiones; es una característica del conocimiento humano-dice con intención-de la que desconocemos su correlato neurofisiológico 32 .

La réplica de Berlin ${ }^{33}$ parece expresar sólo cautela ante los componentes instrumentales del conocimiento científico: el problema es, dice, que la opción tecnológica sea realmente tal, una decisión metodológica y no simple aplicación metódica del conocimiento disponible sin reserva reflexiva alguna; en tal caso sería una intervención puramente instrumental, lo que no impediría que fuera, bajo ciertos puntos de vista, exitosa. Berlin cree que hay que prevenir esa posibilidad. La crítica al determinismo no es intrusismo metafísico sino determinación teórica de que los seres humanos no son cosas. La réplica parece defensiva y moralista ${ }^{34}$. Para valorarla hay que situarla en su contexto que, me parece, no es otro que el de la tercera antinomia kantiana. Hampshire cree que las proposiciones de las ciencias humanas incluyen un conocimiento objetivo y contrastable, obtenido a partir de su doble visión y que no encierra, por tanto, un nexo conceptual con la libertad; cree que es posible diferenciar esas proposiciones de las que se refieren a la libertad y decisión del sujeto. En éstas no hay doble visión: la autopredicción -frases como «sé que haré $\mathrm{x}$ »- carece de valor informativo y sólo expresa la presencia de un yo que decide. En otras palabras: hay criterios formales para discernir si hablamos de una acción como objeto o como decisión. En el primer caso, será un objeto, peculiar, sí, pero que al no incluir a la libertad como componente objetivo, no escapa a regularidades propias de la ciencia.

31 Ibid., p. 67

32 Ibid., p. 79.

33 I. Berlin 1988, pp. 24 ss.

34 Además del artículo que estudiamos, hay que tener en cuenta I. Berlin, 1981 y en I. Berlin 1983a, «'De la esperanza y el miedo liberados'», pp. 281-318. 
Berlin, por su parte, mantiene 35 que los problemas de acción escapan a los criterios formales porque en ellos hay siempre aspectos -valores, fines, preferencias- vinculados a la libertad. El análisis tiene que ser, entonces, empírico pues un discernimiento formal no tendría en cuenta el alcance de tales aspectos. Desde su perspectiva, una confianza como la de Hampshire en la diferenciación formal equivale a confundir el ámbito del objeto. No es que no podamos indagar la acción o la historia sino que no podemos descansar, a esos efectos, en regularidades o en series causales. Eso sería tomar al determinismo, un principio regulativo para la investigación de la naturaleza, como componente constitutivo de todo acontecer mundano ${ }^{36}$. La metábasis eis állo génos iría aquí justo en sentido contrario al de Hampshire.

Pero ¿por qué este posicionamiento de Berlin? Sus raíces están más cerca de Hume que de Kant. En «El erizo y la zorra»37, Berlin contrasta al Tolstoi obsesionado -como el erizo de Arquíloco-por una sola idea, la del determinismo en la historia, con el Tolstoi novelista, sensible a lo diverso, que capta -como la zorra del poeta griego- la variedad de los mundos individuales; desarrolla en el ensayo la idea de marco de la experiencia. Los seres humanos no están primariamente ante su objeto, sino inmersos en múltiples relaciones con su entorno que son anteriores a toda objetivación. Llegamos a conocer desde esta inmersión práctica en la que se anudan múltiples y sutiles relaciones ${ }^{38}$ que forman, dice Berlin, la textura de la vida humana ${ }^{39}$. Este haz de relaciones, que encierra aspectos subjetivos y objetivos sin diferenciación posible, es el marco general de la experiencia. El pensamiento, la acción inteligente brotan y se sitúan en él. Este conjunto de relaciones básicas no podemos llegar a objetivarlo porque en él es donde adquieren sentido nuestras categorías y estructuras básicas de lenguaje; no podemos observarlo porque, en algún sentido, forma parte de nosotros mismos 40 . Sin embargo, desde ese marco es desde donde constituimos objetos y emitimos juicios decisivos ${ }^{41}$ aunque sin poder calificar a esta actividad de racional: esta palabra - y su antónimo- adquieren sentido dentro de tal marco.

35 I. Berlin 1988, p. 138 , nn. 10 y 11.

36 Esta es la fascinación del determinismo que Berlin relaciona con el ideal trascendental kantiano (I. Kant, Crítica de la razón Pura, Dialéctica Trascendental, Libro II, Secc. III, caps. I y II).

37 I. Berlin 1981.

38 Berlin alude con frecuencia a los impalpables hilos que vinculan la comunidad humana. La metafora de Burke la asocia normalmente, salvo quizá en un pasaje de su monografía de Marx, donde la aplica a la sociedad civil, a la formación de la identidad humana.

39 I. Berlin 1981, pp. 130-131.

40 Ibid., p. 132.

41 Ibid., p. 136. 
Aceptar esta relación no implica renunciar a la ciencia ni al pensamiento crítico sino reconocer que son actividades posteriores a aquella relación inobjetivable, y que su ejercicio, por tanto, exige ir acompañado de un cierto «sentido de la realidad» 42 que las sitúe en el conjunto de la existencia. No hay renuncia a la autonomía del pensamiento ni a su libre capacidad de invención, pero si se advierte que ambas nacen en un medio que no podemos controlar, hay que admitir que toda creación tiene un envés de gratuidad y toda determinación la sombra de la contingencia. Berlin tiene pues también su doble visión. Pero no es la dialéctica entre reflexión y conceptualización, sino que ambas se oponen a una relación prerreflexiva del sujeto con su mundo de la que ambos surgen. Esta doble visión no camina hacia la objetivación sino, como la metacrítica, vuelve insistentemente el rostro hacia la situación en la que objeto y sujeto se enfrentan y diferencian. No resuelve, por tanto, la antinomia, sino que se sitúa en ella, porque no quiere que la reificación de un lenguaje -lo veíamos al fin del epígrafe anterior-ni la precipitación de un concepto recorte las posibilidades de experiencia y de existencia.

Desde esta doble dimensión, la reserva ante los aspectos instrumentales del conocimiento recibe su base teórica: toda positividad aplicada al ser humano tiene el riesgo de ignorar-otros dirían, olvidar-aspectos humanos previos a la objetualización. La reflexión cobra un valor distinto: es, más que un recurso cognoscitivo para la conceptualización, un trabajo que rastrea las múltiples relaciones que forman nuestras vidas, sus innumerables hilos, como decía Burke, y que no se detiene en la limpidez de sus resultados sino que incorpora la diversidad de situaciones en las que se mueve. En este planteamiento cobran nuevo sentido cuanto dijimos antes sobre el valor de la capacidad de juicio y de la pragmática: no apuntan a una mejor conceptualización, sino a hacer presente este trasfondo de la experiencia.

Mantener la tensión de la antinomia no es fácil. Para Berlin, la tentación del pensamiento moderno, común a ilustrados y reaccionarios, ha sido suprimirla, cerrar su indeterminación y establecer alguna forma última de identidad. Cree que en esto coincide Voltaire con De Maistre ${ }^{43}$. Quizá uno de los pensadores que se mantienen sobre aquél difícil suelo sea Hume. Leyendo a Berlin se hace patente el sentido de la confesión de Hume de estar ante «un sistema filosófico monstruoso producto de dos principios contrapuestos» 44 . Hume mantuvo sin duda dos dimensiones opuestas de la experiencia, las dos

42 Ibid., p. 135.

43 Este paralelo puede verse en I. Berlin 1990, pp. 158-160. Es quizá interesante señalar que el paralelo de Berlin tiene, entre otros, el fundamento de la frialdad de ambos pensadores. Hume, por el contrario, no desdeñaba la pasión.

44 D. Hume 1984-1985, p. 215. 
funciones que podrían llamarse trascendentales de la imaginación 45 : una de ellas, pese a ser mitológica, mantiene la continuidad del mundo y es por ello ámbito de la acción, por lo que para Hume es la que nos abre a la realidad; la otra es el espacio de la inteligencia crítica. Deleuze llama a la primera constituyente y a la segunda, espacio de objetos, constituida. La analogía con la propuesta de Berlin es evidente. Duque piensa que Hume mantiene esa contradicción como medida contra cualquier dogmatismo. Berlin, desde su posición, puede rechazar la hipóstasis de los lenguajes privilegiados y la exclusividad de conceptos racionales ${ }^{46}$ para comprender tal acontecer. La indagación de la acción y de la historia no se contenta con principios formales y recurre a análisis empíricos porque es la manera de no ceder ni al dogmatismo de las esencias ni al de los hechos.

Este planteamiento, precisamente por sus raíces humeanas, tiene dos consecuencias. La primera es que la libertad y el saber no son coextensivos. La aspiración moderna a desmitificar, a iluminar con el conocimiento los rincones de la subjetividad y el curso de la naturaleza quizá nos libere de angustias, miedos y de falsas esperanzas. Pero no acrecienta necesariamente la libertad porque el proceso de racionalización quizá suprima, dice Berlin, $m i$ identidad de artista ${ }^{47}$. Berlin coloca a la libertad en el amplio marco de relaciones previo a la conceptualización. Algunos han visto aquí una influencia más de Hume: devolver a la racionalidad a la cercanía de la pasión 48 . A mi juicio no es sino un paso radical de la crítica de Berlin a la modernidad: combatir el desplazamiento racionalista subrayando la importancia de la opción. La segunda consecuencia es el escepticismo. Desde la concepción berliniana de la experiencia la objetividad del conocimiento parece suspenderse.

$\mathrm{X}$

En Berlin hay ciertamente un moderado escepticismo, quizá otra influencia de Hume. Lo hemos visto rechazar la pretensión de un saber completo pero también cuestiona el ideal galileano de la ciencia ${ }^{49}$ y observa que una objetividad de las leyes naturales tal como la propone el falsacionismo popperiano prescinde de muchos aspectos de las cosas. Las leyes naturales no son más que el resultado de nuestra capacidad para modelar categorialmente el acontecer natural ${ }^{50}$. Modelar

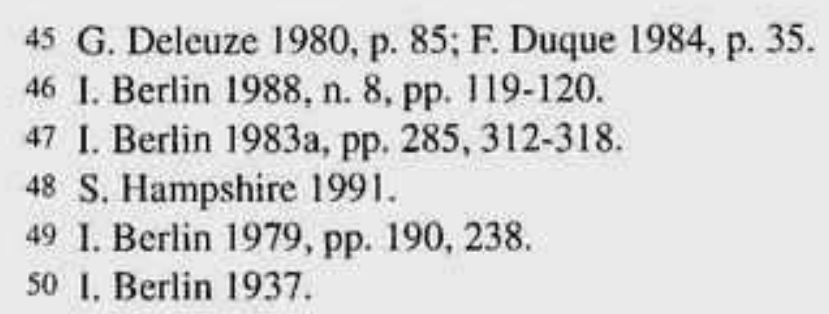


en un sentido débil: inscribimos en modelos lógico-matemáticos aspectos del acontecer natural para establecer entre ellos correlaciones. No hay aquí, sin embargo, relativismo porque las hipótesis científicas se proponen con una pretensión de validez intersubjetiva, esto es, en un lenguaje público, organizado por conceptos y categorías -que no son producto de determinaciones psicológicas o sociales ${ }^{51}$-que permiten compartir un mundo bajo ciertos intereses cognoscitivos.

La ciencia sería, pues, un ejercicio de la racionalidad, cuya objetividad se caracteriza por un interés cognoscitivo que es, básicamente, la predicción 52 y por conceptos y prácticas de observación cuyo alcance se define mediante un metalenguaje formal o por el consenso entre especialistas. Una ciencia se consolida como dominio autónomo de investigación ${ }^{53}$ cuando alcanza métodos y criterios precisos para determinar sus relevancias, evaluar sus pruebas y organizar sus argumentaciones, y fija así con claridad qué preguntas puede responder y cuáles no ${ }^{54}$. Son condiciones de inspiración pragmática y reflexiva y entrañan dos consecuencias: a) que cada ciencia excluye de sí conceptos y categorías que puedan distorsionar su objeto y b) que ha de refinar las especificaciones bajo las que un objeto puede acceder a su ámbito55.

Esta noción de objetividad respeta la idea de coherencia categorial y el papel atribuido a las determinaciones dentro del marco general de la experiencia. No cabe hablar de escepticismo; sí de la necesidad de un feed-back reflexivó: si una ciencia, en el curso de su investigación tropieza con fenómenos que desbordan sus conceptos, deberá buscar un ámbito más general de reflexión para resolver el problema planteado.

¿Cuál es la objetividad de la historia y de las ciencias humanas? Lo primero que ha de destacarse es que su interés cognoscitivo es diferente: buscan sobre todo establecer niveles de profundidad o densidad para comprender la acción y el acontecer. Esto plantea hondas diferencias entre sus procedimientos y el de la ciencia. No pueden aspirar, como ésta, a una especificación formal cada vez más fina porque esto le impediría disponer de objetos ricos y densos 56: el texto histórico parece, al contrario que el de la ciencia, una «amal-

51 La idea de Berlin de relativismo pueden verse sobre todo en I. Berlin 1988, pp. 154-155 y nota 17; 1. Berlin 1990, pp. 78-84. Que la crítica adecuada al relativismo es sólo posible desde la generalidad, es una idea cara a Adorno: así, en la introducción a la Dialéctica Negativa.

52 I. Berlin 1983a, p. 74.

53 Ibid, pp. 33 y 242; I. Berlin 1982, p. 29; J. L. Austin 1975, p. 215

54 I. Berlin 1988, p. 157; 1. Berlin 1983a, pp. 29 y 32, 248-249; I. Berlin 1982, pp. 24-25. A principios de los sesenta, Berlin sustituye la idea de este lenguaje formal por la de que conceptos y prácticas se acepten "por la gran mayoría de especialistas » y su aptitud «para incorporarse en un libro de textom (1. Berlin 1983a, p. 240).

55 I. Berlin 1988, p. 157; I. Berlin 1983a, p. 198.

56 I. Berlin 1983a, pp. 204-206. 
gama, un rico cocimiento compuesto de elementos en apariencia dispares»57. Tampoco puede la historia excluir determinadas categorías o conceptos e incluso parece no contar con algunos que les sean exclusivamente propios. Cualquier exclusividad puede pagarse con la incapacidad para dar cuenta de lo que realmente nos interesa del acontecer ${ }^{58}$. Su proceder consiste más bien en entretejer diversos «conceptos y proposiciones generales, a primera vista independientes lógicamente» para hacer que «vengan al caso de una situación dada de la mejor manera posible». Su trabajo se centra en lo que más arriba llamamos capacidad de juicio. Esto da razón de las generalizaciones blandas de la historia, a las que me he referido en diversas ocasiones, y sobre todo de un procedimiento por el que a los nítidos conceptos científicos, el historiador y el analista político oponen otros «mucho más ricos en contenido y menos simples y perfilados en su estructura lógica» 59 . Finalmente, la carencia de principios formales se manifiesta en la selección de relevancias que reposa en la valoración, en la importancia que, según nuestra creencia, atribuimos a ciertos elementos del acontecer 60.

El quehacer de la historia y de ciertas ciencias humanas ${ }^{61}$ queda así precisado con claridad. El problema es la objetividad que pueda lograr. La objetividad de la ciencia aunque modesta, se satisfacía por precisar formalmente un ámbito de generalidad, dado por un lenguaje apropiado. La historia carece de un marco formal y reposa en el lenguaje común y en valoraciones. Es necesario seguir otra vía para lograr un nivel de generalidad y que no se reduzca a una reflexión, rica, sí, pero recluida en cada época, cada cultura, cada historiador 62 .

Si el texto histórico puede ofrecer algo parecido a un mundo compartido, lo consigue por la capacidad de juicio. El acuerdo o desacuerdo que mantengamos con él no podremos precisarlo mediante un algoritmo ${ }^{63}$ sino por la reflexión. Es lo que más arriba dijimos del dictamen de un juez y ahora podemos

57 Ibid., p. 220.

58 I. Berlin 1988, p. 157.

59 Ibid., p. 161.

60 lbid., pp. 161-162.

61 No está claro cuál de ellas. Berlin en ocasiones considera que la economía y la psicología han logrado su autonomía y a veces las hace acompañar por la sociología. En otras ocasiones, la primera y la última son excluidas, mientras que su desconfianza del mercado y de la planificación no dejan muy en claro bajo qué concepto la economía es una ciencia. De todas formas, merece la pena recordar aquí que la ciencia, en los momentos en que algunos de sus descubrimientos parecen cuestionar sus fundamentos, tal vez su paradigma, debe, en criterio de Berlin volver a la filosofía (I. Berlin 1982).

62 Recuérdese lo dicho más arriba sobre Gardiner y la generalidad de la Historia.

63 A este respecto es interesante la discusión sobre el experimento crucial (K. R. Popper 1983, pp. 291 ss.) y las observaciones sobre el algoritmo en R. Rorty 1983. 
extenderlo al texto histórico y quizá también al informe explicativo de la elaboración de cuestionarios de indagación social: examinamos si las relevancias elegidas son banales o importantes, si los elementos de prueba se han ponderado según los métodos que por sí mismos parecían exigir, cuál es el tratamiento de los hechos, cuál la coherencia entre criterios de interpretación, cuáles los nexos entre pruebas y conclusión ${ }^{64}$. Estos criterios no reposan en una base metodológica formal, sino que brotan en la relación que guardamos con el texto que se propone y con el saber de nuestra época. El punto de apoyo de tales criterios es que garanticen un mundo en común: no un paisaje ante los ojos - en el caso de la historia- ni -por lo que al cuestionario se refiere- un proyecto articulado por una sola idea, sino un territorio en el que se puedan compartir actitudes y puntos de vista diversos y amplios ${ }^{65}$. La virtud de tales criterios no es tanto decidir si algo es verdadero o falso, cuanto activar la discusión porque generan campos de oposición significativa -lo plausible y lo inverosímil, lo riguroso y lo gratuito-que es donde al fin el discernimiento de lo objetivo -frente a subjetivo-puede tener sentido 66 .

El enfoque debe ya resultarnos familiar: la capacidad de juicio puede compartirse por razones pragmáticas y reflexivas, pero su punto de apoyo es la referencia a lo que ya conocemos como marco general de nuestra experiencia. La cuestión, ahora, es saber cómo podremos acercarnos al cúmulo de relaciones no conceptualizables de otra época o de otra cultura, a los que forman el trasfondo de la experiencia, el mundo, de quienes sustentan valores o modos de vida diferentes y que son nuestros interlocutores tanto en torno al texto histórico, como en la indagación sociológica o el análisis político. Para Berlin esto es posible gracias a una «capacidad de comprender los hábitos de pensamiento y de acción encarnados en las actitudes y en los comportamientos humanos» 67 , es decir a la comprensión.

Berlin toma este concepto, como hizo Gardiner, de la tradición filosófica alemana, separándolo también del psicologismo del primer Dilthey y de las referencias hegelianas de Collingwood. Pero lo conecta fuertemente al lenguaje gracias a su lectura de Herder y Vico: la idea de comprensión reposa en nuestra experiencia de hablantes. Cuando asimila la Verstehen a la fantasia de Vico y a la Einfühlung herderiana 68 , lo que hace es profundizar en su propia noción de usos de lenguaje. Estos no se limitan a la objetivación del mundo, sino que ofrecen plataformas para la comunicación porque engarzan relacio-

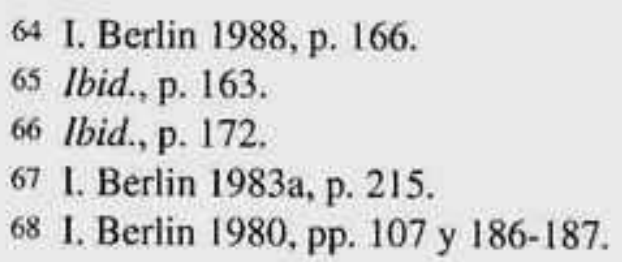


nes diversas y diferenciadas entre sujeto y objeto. Ciertos usos del lenguaje escapan al concepto, como es el caso del arte que no ofrece un mundo nuevo, sino una nueva mirada, es decir, una nueva vía para compartir el mundo69. La Verstehen no conduce entonces a otros mundos, sino a otras formas de experiencia, distintas de la nuestra pero en la que podemos reconocer un ejercicio como el nuestro para relacionarse con el mundo. Lleva, en palabras de Berlin, a «una pauta de actividad» que no podemos «explicitar en su totalidad (y menos aún organizar en un sistema)», pero sí «entender, recordar o imaginar» sobre el supuesto de nuestro modo de organizar nuestro mundo 70 . La comprensión es, como vimos en Gardiner, una peculiar actividad de la imaginación, pero si logra entrar en otras culturas o épocas es porque explora no otros objetos, sino otras formas de ser autor y agente, otras formas de establecer y usar el lenguaje, otras formas de relacionarse con el entorno; porque nos acerca a otros marcos generales de experiencia.

Para este acercamiento, Berlin toma otro concepto de Dilthey, la Wirkungszusammenhang ${ }^{71}$, que traduce como la organización general de la experiencia de una cultura, de una época o de una visión del mundo, tomada no en el terreno de las determinaciones objetivas acabadas, sino en el de las relaciones previas, el de las expectativas de una sociedad, no sólo las que están vinculadas al interés o a la norma, sino, sobre todo las que están unidas a fines posibles, identidades tentativas, al mito, a la simbología. Para subrayar este carácter abierto, Dilthey usa un término kantiano, la apprehensio ${ }^{72}$.

La comprensión y esta caracterización del marco de la experiencia son la base de la objetividad de la historia y de las ciencias humanas a las que nos hemos referido. Aún podríamos preguntar si es plausible este acercamiento. Berlin piensa que lo es gracias a una característica exclusiva del objeto del acontecer humano que ya señalara Vico 73 . El objeto natural nos será siempre externo, no así el acontecer humano con el que siempre guardamos una relación interna por que en él somos autores y actores: de la danza y el rito, del ceremonial y la norma no sólo conocemos el qué y el cómo sino el por qué. Los conocemos, por así decir, desde dentro. Este contacto directo con el objeto es el que permite lanzar hipótesis sin recurrir a concepto e interpretar con osadía. Porque lo hacemos desde el mismo «contexto en el que pensamos y actuamos, desde el que esperamos que se nos comprenda y responda» 74 y sin el que no es

69 Ante las propuestas del arte sólo cabe el reconocimiento de una estructuración diferente de la experiencia que, sin embargo, puede iluminar decisivamente a la nuestra (I. Berlin 1939, p. 527).

70 I. Berlin 1983a, p. 216.

71 lbid., p. 233. Para una precisión eficaz del concepto, W. Dilthey 1978, p. 72, nota.

72 Auffassung. I. Kant 1981a, introducción, epígrafe VIII; W. Dilthey 1978, p. 29.

73 G.-B. Vico 1973-1981, epígrafe 331.

74 I. Berlin 1983a, p. 216. 
concebible la textura de la vida humana. Si tratáramos de cuestionar tal contexto analíticamente de manera global, ni aun el pensamiento sería posible75. La objetividad del discurso histórico reposa así en la comunicación, pero no mediada por el concepto, sino por la experiencia de vivir humanamente.

Aún queda una pregunta: si esta idea de objetividad como comunicación no conduce al fin a un mero relativismo tanto sobre las distintas escrituras de la historia como respecto a las diversas formas de vidas. Berlin es terminante: hay textos, propuestas de acción o formas de vida ante los que la comunicación se rompe porque apenas podemos reconocer en ellos una experiencia que merezca la calificación de humana. La comunicación se rompe ante la historia de los vencedores tanto como ante las de los vencidos: ni la dominación ni el resentimiento son humanos -aunque Berlin diría que el segundo caso siempre promueve la solidaridad ante el dolor-. La comunicación se rompe también ante la violencia y ante cualquier motivo que fuerce a alguien a proceder inhumanamente. Ante tales conductas no es lícita la tolerancia. Ante las demás ésta será posiblemente insuficiente porque, en su variedad, exigen algo más, el pluralismo.

\section{REFERENCIAS BIBLIOGRÁFICAS}

ADORNO, Th. W. 1984: Dialéctica negativa, tr. J. M. Ripalda, rev. por J. Aguirre. Madrid: Taurus.

AUSTIN, J. L. 1975: Ensayos filosóficos, tr. A. García Suárez. Madrid: Revista de Occidente.

AUSTIN, J. L. 1982: Cómo hacer cosas con palabras Palabras acciones, tr. G. R. Carrió y E. A. Rabossi. Barcelona: Paidós.

BERLIN, I. 1937: «Induction and Hypothesis», Proceedings of the Aristotelian Society, vol. sup. 16 , pp. 63-102.

1939: «Review on Britton K. Communication». Mind, 48, pp. 518-27.

1979a: Pensadores rusos, tr. J. J. Utrilla. México: Fondo de Cultura Económica. 1979b: The Age of Enlightenment. Oxford: Oxford Univ. Press.

1980: Vico and Herder. Two Studies in the' History of Ideas. London: Chatto \& Windus.

1981: El erizo y la zorra. Ensayo sobre la visión histórica de Tolstoi, tr. M. Muchnik. Barcelona: Muchnik.

1982: «Una introducción a la filosofía». Entrevista en B. Magee (ed.): Los hombres detrás de las ideas. tr. J. A. Robles García. México: Fondo de Cultura Económica.

75 Ibid., p. 196. Esta apreciación podría compararse con las de Sellars 1963, p. 170 y J. Kristeva 1981, t. I, p. 112). 
1983a: Conceptos y categorías, tr. F, G. Aramburo. México: Fondo de Cultura Económica.

1983b: «Introducción» a H. G. Schenk, El espiritu de los románticos europeos. tr. J. J. Utrilla. México: Fondo de Cultura Económica.

1983c: Contra la corriente, tr. H. Rodríguez Toro. México: Fondo de Cultura Económica.

1988: Cuatro ensayos sobre la libertad, tr. B. Urrutia, J. Bayón y N. Rodz. Salmones. Madrid: Alianza.

1990: The Crooked Timber of Humanity, ed. Henry Hardy. London: John Murray. 1993: The Magus of the North. J. G. Hamann and the Origin of the Modern Irrationalism, ed. H. Hardy. London: John Murray.

CARR, E. H. 1984: ¿Qué es la historia? tr. J. Romero Maura, Barcelona: Ariel.

DELEUZE, G. 1980: Empirisme et subjectivité. Essai sur la nature humaine selon Hume. Paris: PUF.

DILTHEY, W. 1978: El mundo histórico, en Obras Completas, t. VII, tr. E. Imaz. México: Fondo de Cultura Económica.

DUQUE, F. 1984: «Estudio preliminar» a D. Hume 1984-1985.

GARDINER, P. 1961: The Nature of the Historical Explanation. Oxford: Oxford University Press.

1977: «Review on Berlin, I.: Vico and Herder: Two Studies in the History of Ideas». History and Theory, 16, pp. 45-51.

GINZBURG, C. 1994: Mitos, emblemas, indicios. Morfología e historia. tr. C. Cattropi, Barcelona: Gedisa.

HAMPSHIRE, S. 1949: «Subjunctive Conditionals», Analysis, 9 (1949), pp. 9-14. 1967: «Philosophy and Madness», Listener, 87, pp. 289-92. 1979: «Freedom and Explanation or Seeing Double», en A. Ryan (ed.), The Idea of Freedom. Oxford: Oxford University Press. 1991: «Nationalism», en E. y A. Margalit (eds.), Isaiah Berlin. A Celebration. London: The Hogarth Press.

HUME, D. 1984-1985: Tratado sobre la naturaleza humana, tr. F. Duque. Barcelona: Orbis-Ed. Nacional, 3 vols.

KANT, I. 1981a: Crítica del juicio, tr. M. García Morente. Madrid: Espasa Calpe. 1981b: »Qué es la Ilustración» en Filosofía de la historia, tr. E. Imaz. Madrid: Fondo de Cultura Económica.

KRISTEVA, J. 1981: Semiótica, tr. J. Martín Arancibia. Madrid: Fundamentos.

MOMIGLIANO, A. 1976: «On the Pioneer Trail», New York Review of Books, 11 de noviembre, pp. 33-8.

POPPER, K. R. 1983: Conjeturas y refutaciones. El desarrollo del conocimiento científico, tr. I. Grasa, Barcelona: Paidós.

RORTY, R. 1983: La filosofía y el espejo de la naturaleza. tr. J. Fernández Zulaica. Madrid: Cátedra.

SELLARS W. 1963: Science, Perception and Reality. New York: The Humanities Press. VICO, G.-B. 1973-81: Principios de una ciencia nueva, 4 vols., tr. M. Fuentes Benot. Buenos Aires: Aguilar. 
WEBER, M. 1982: «Estudios críticos sobre la lógica de la ciencia de la cultura», en Ensayos sobre metodología sociológica, tr. J. L. Etcheverry. Buenos Aires: Amorrortu.

1985: «Roscher y Knies y los problemas lógicos de la escuela histórica», en El problema de la irracionalidad en las ciencias sociales. tr. L. Simón y J. M. García Blanco. Madrid: Tecnos.

WHITE, M. 1956: Review on «Historical Inevitability». Perspectives USA, 16, pp. 19-26.

Juan Bosco Díaz-Urmeneta Muñoz es profesor titular de Estética y Teoría de las Artes en la Universidad de Sevilla. Autor de Individuo y racionalidad moderna. Una lectura de Isaiah Berlin (Sevilla: Universidad de Sevilla, 1994), así como de la versión castellana, introducción y notas a I. Berlin, El Mago del Norte. J. G. Hamann y los orígenes del irracionalismo moderno (Madrid: Tecnos, 1997).

Dirección postal: Universidad de Sevilla, Facultad de Ciencias de la Información, Cl. Gonzalo Bilbao, 7-9, Sevilla. 